\title{
Paideia nutricia: las artes del saber y del comer en Luciano ${ }^{1}$
}

\author{
Pilar Gómez Cardó \\ Universitat de Barcelona \\ Departament de Filologia Grega \\ pgomez@ub.edu
}

Recibido: 20 de octubre de 2010

Aceptado: 30 de noviembre de 2010

\begin{abstract}
RESUMEN
Un tema recurrente en la literatura griega de época imperial romana es la crítica contra los falsos filósofos. Luciano censura con especial dureza su impostura e indigna actitud en el banquete y en la celebración simposial, donde los hombres pretendidamente sabios sólo están interesados en satisfacer un insaciable apetito. El objetivo de este trabajo es analizar cómo se concreta esa censura hacia los filósofos en el ámbito del banquete por contraposición a la figura del parásito, ya que el comportamiento alimentario de los falsos filósofos los aproxima a la figura del parásito. Si el objetivo del parasitismo es la felicidad, los parásitos no persiguen nada distinto a los filósofos, tal como Luciano los presenta en el Simposio o Lapitas. Sin embargo, la superioridad de la parasitike techne defendida por Simón en Acerca del parásito, consiste en alcanzar ese mismo objetivo sin la hipocresia y el ridículo de que tantas veces son objeto todos los falsos pepaideumenoi.
\end{abstract}

Palabras clave: Luciano, simposio, filósofos, parásitos

\begin{abstract}
A topic in the Greek literature of the Roman imperial period is the attack against the false philosophers. Lucian condemns with special hardness their shameful behaviour in symposiac gatherings, where the wise men are only interested in satisfying an insatiable appetite.

The purpose of this paper is to analyse how Lucian criticises the philosophers at the banquet in comparison with the parasite, because the eating patterns of false philosophers make them similar to parasites. If the aim of parasitism is happiness, then parasites do not pursue anything different from philosophers, as Lucian makes clear in The Symposium or the Lapiths. Nevertheless, in The Parasite, Simon argues that the parasite's techne is superior, inasmuch as it achieves the same aim as the philosophers, without the hypocritical and ridiculous attitudes of the false pepaideumenoi.
\end{abstract}

Key words: Lucian, symposium, philosophers, parasites

\footnotetext{
${ }^{1}$ Este trabajo se ha realizado en el marco del proyecto «Recrear el logos: narrativas griegas de época imperial» (FFI2009-08858), financiado por el MICINN y dirigido por la profesora Francesca Mestre.
} 
«Pero ¿no te sonrojas al llamarte a ti mismo parásito?». La respuesta de Simón a esta pregunta de Tiquíades es contundente: «En absoluto, me avergonzaría si no lo dijera ${ }^{2}$. Sin embargo, la seguridad que reflejan las palabras de Simón contrasta con la aflicción de Filosofía cuando acude a Zeus «excitada y llorosa, como si hubiera sufrido una gran ofensa», porque se siente traicionada por aquellos hombres que por su porte y mirada, por su manera de andar y de vestir se presentan como sus discípulos, pero cuya abominable existencia está colmada de ignorancia, de osadía y de vanidad ${ }^{3}$.

Estas dos citas, que pertenecen a sendas obras de Luciano, nos sitúan cada una de ellas ante sendos temas bien conocidos en la tradición literaria griega, especialmente gracias al testimonio de los poetas cómicos: la figura del parásito y la disputa entre escuelas filosóficas, en la que subyace siempre una notable intención crítica. El objetivo de este trabajo es analizar cómo el samosatense concreta esa censura hacia los filósofos en el ámbito del banquete por contraposición a la figura del parásito. Luciano no califica explícitamente a los filósofos de parásitos, pero a partir de las palabras de $s u$ parásito, unidas a la constante caricatura de los filósofos cuando participan en un festín, se entiende que éstos son para él los auténticos vividores.

\section{FILÓSOFOS Y CENTAUROS}

Las obras de Luciano son fruto de un complejo mecanismo literario que delata, sin duda, la habilidad y agilidad del samosatense, mucho mayores que las de sus contemporáneos, en el uso simultáneo tanto de la literatura del pasado como de los métodos escolares propios de su presente histórico, una época de retórica aplicada ${ }^{4}$. De este modo, si bien puede ser inexacto hablar de temas propiamente lucianescos, no resulta difícil identificar combinaciones lucianescas de Platón, de Aristófanes, de los poetas, de los historiadores, de los oradores ${ }^{5}$; máxime cuando Luciano mismo reconoce como su aportación personal en el proceso de creación literaria el haber logrado la fusión entre filosofía y comedia ${ }^{6}$, al tiempo que celebra como su principal aventura literaria haberse alejado de la retórica ${ }^{7}$.

Un tema propio de la comedia es la polémica entre escuelas filosóficas, en la que, especialmente los epicúreos, son presentados como unos presuntuosos ignorantes faltos de conocimientos, pródigos en prácticas obscenas y depravados cuya existencia se cifra sólo en el placer. Esta valoración es, ciertamente, inexacta por exagerada,

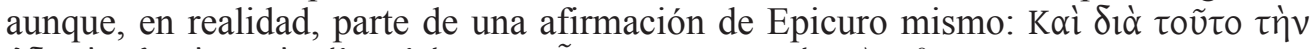

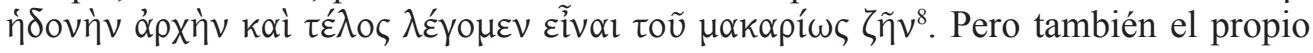

\footnotetext{
${ }^{2}$ Luc. Par. 2

${ }^{3}$ Luc. Fug. 3-4.

${ }^{4}$ Cf. Reardon (1971: 199-231).

${ }^{5}$ Cf. Bompaire (1958: 330-332); Anderson (1976: 21-22).

${ }^{6}$ Cf. Luc. Prom. Es 6-7; Bracht Branham (1989: 38-43); Romm (1990: 74-98); Mestre \& Gómez

${ }^{7}$ Por haber sido abandonada, Retórica lleva al Sirio (a Luciano) ante los tribunales, como explica en Bis accusatus; cf. Mestre (1997: 21-31).

${ }^{8}$ Epicur. Ep. 128, 11.
} (2001: 111-122). 
mundo de la comedia, imaginario, utópico, tiene como objetivo la felicidad, que, en el ideario colectivo, va unida a los placeres del amor y del comer. La cultura antigua, por otra parte, ofrece un escenario privilegiado para alcanzar ese objetivo en el banquete, punto de encuentro entre el acto primario de alimentarse y la vida civilizada ${ }^{9}$. Así pues, dar satisfacción a la necesidad básica de nutrición corresponde al ámbito de la naturaleza, de la $\varphi$ v́øı, como bien ilustra el mito griego, al identificar la áurea edad de Cronos, precisamente, con el momento en que la tierra ofrecía a los hombres alimentos de forma espontánea, sin necesidad de ser cultivada ${ }^{10}$. El banquete, en cambio, es una institución social, cívica, un lugar idóneo para reencontrar el saber y a los amigos, donde los huéspedes se reúnen a fin de poder compartir «no sólo manjares, vino y golosinas, sino también conversaciones, esparcimientos y afabilidad que acaban en estima», como afirma Plutarco ${ }^{11}$. Y es en un contexto simposial, concebido tradicionalmente como un espacio de intercambio de opiniones y de enseñanzas de todo tipo, incluida la retórica ${ }^{12}$, de exhibición del saber, e incluso de erudición, de paideia vehiculada también a través del humor ${ }^{13}$, donde todavía Plutarco define la filosofía como

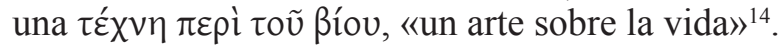

Por ello, la impostura y la indigna actitud de los filósofos que Luciano gusta de censurar $^{15}-\mathrm{y}$ que constituye un tópico recurrente en la literatura de su época ${ }^{16}-$, se revela especialmente inapropiada en el marco del banquete y de la celebración simposial, en la que el vino desempeñó siempre un papel central, pero nunca como un fin en si mismo, sino como anticipo y prólogo de la palabra -y, en particular, de la palabra filosófica-, que, idónea, aporta al banquete mesura y oportunidad ( Kaı póv $)^{17}$. Luciano con su sagaz ironía ilustra en numerosos pasajes y con diversos ejemplos cómo demasiado a menudo, los filósofos se apresuran para llegar los primeros a casa de los ricos y allí comen con afán y beben sin medida, sin tener en cuenta los límites que marca una mínima corrección ${ }^{18}$.

Plutarco admite y defiende que la filosofía auténtica no debe permanecer ajena

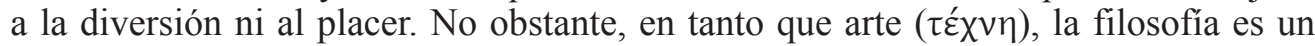
producto de cultura, un artificio, una convención, que se sirve de palabras y argumentos, quizás para alejar con esos recursos a los hombres de su condición natural, pero

\footnotetext{
${ }^{9}$ Esto explica la presencia o la ausencia de comida y de recursos alimenticios en numerosos mitos griegos relativos a la fundación de nuevas poblaciones; $c f$. Jufresa \& Fau (2001: 189). Por su parte, Garnsey (1999: XI), afirma: «Greeks and Romans, rich or poor, were, obsessed with food».

${ }^{10}$ En cambio, ahora, incluso durante las fiestas en honor de Cronos, solamente los cocineros y los pasteleros deben trabajar; $c f$. Luc. Sat. 13.

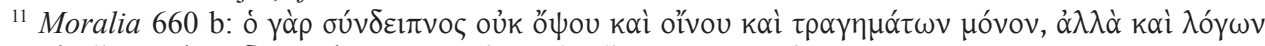

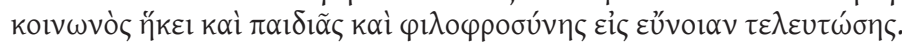

${ }^{12}$ ibidem 612 d; González Julià (2009: 66-67).

${ }^{13}$ Cf. Bracht Branham (1989: 104-123); Gómez \& Jufresa (1999: 263); Anderson (2000: 318); Romeri (2002: 247-321).

${ }^{14}$ Plu. Moralia 613 b. Esta afirmación, de resonancia estoica, es formulada por Plutarco en respuesta a la pregunta de si es posible filosofar en un banquete o en una reunión simposial.

${ }^{15}$ Cf. Brandâo (2001: 51-64).

${ }^{16} C f$. Hall $(1981: 138,190)$.

${ }^{17}$ Plu. Moralia 613 b. Sobre la vinculación del vino y la palabra, véase Romeri (2002: 171-189).

${ }^{18}$ Cf. Luc. Pisc. 34; Fug. 19.
} 
mitigando, tal vez sólo en apariencia, instintos más primarios, que el ser humano por condición natural no sabe, no quiere o no puede renunciar a satisfacer. Así se explica que los filósofos, cuando asisten a un banquete y se les ofrece una copa de vino o un trozo de carne, olviden con facilidad quiénes son y qué han aprendido a decir o qué deben hacer para justificar su posición de filósofos, y, al traicionarlos su propia naturaleza, desvelen entonces una hipócrita conducta y un falso comportamiento: la

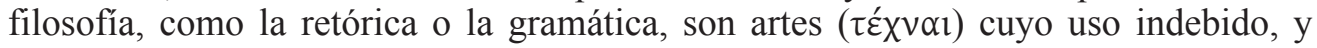
abuso sistemático, hacen merecedores a quienes las practican, sean filósofos, rétores o gramáticos, de burla y escarnio, a pesar de la instrucción y erudición de todos ellos.

Por eso, Luciano no suele dirigir su feroz crítica contra la ideología de las distintas escuelas filosóficas, sino fundamentalmente contra el fraudulento proceder que exhiben sus representantes, cuya impostura merece especial reproche por parte de Luciano cuando observa y describe cómo los filósofos tratan de satisfacer la necesidad primaria de alimento y, por lo tanto, cómo se comportan en el banquete.

Trasicles por la mañana se muestra como un filósofo: sobrio en el vestir, comedido en el andar, pronuncia discursos sobre la virtud, ensalza la frugalidad y censura a quienes sólo piensan en gozar del placer. Pero, llegada la noche, cuando va a la cena, se comporta de un modo radicalmente distinto, como si hubiera bebido el agua del olvido: «arrebata, como un milano, las viandas; da codazos al vecino; se embadurna la barba de salsa; se harta como un perro; se inclina sobre los platos como si esperara encontrar en ellos la virtud; limpia escrupulosamente las bandejas con el dedo, para no dejar ni una partícula de salsa; se queja siempre de su porción, aunque tome el pastel entero o el jabalí solo para él; el colmo de la glotonería y de la insaciabilidad; bebido y borracho no se contenta con el canto y la danza, sino que llega al insulto y la cólera. Además, no para de hablar con la copa en la mano, y en ese momento de manera especial, sobre la moderación y la sobriedad; y esas cosas las dice cuando ya está muy afectado por el vino puro y tartamudea de modo ridículo» ${ }^{19}$.

Trasicles responde al patrón típico del filósofo por su aspecto externo y por sus palabras, pero, al mismo tiempo, el samosatense se burla de él precisamente porque

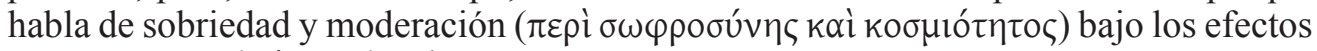

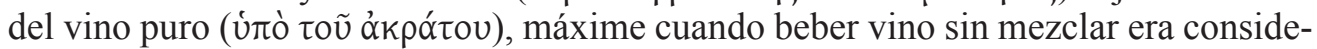
rado una costumbre propia de pueblos bárbaros ${ }^{20}$. El retrato de Trasicles ilustra cómo Luciano arremete siempre contra los seguidores de filosofía para reprocharles una falta de coherencia pragmática al decir una cosa y practicar otra distinta, cuando la vida del filósofo debería ser, en cambio, espejo de sus doctrinas ${ }^{21}$. Por ello son numerosos los pasajes que el corpus lucianeo ofrece a propósito de esa inexistente correlación entre las ideas y las acciones de los miembros de las distintas escuelas filosóficas, casi sin excepción alguna.

Pero Luciano, como otros autores de su época, también incluye, dentro de su extensa producción, una pieza de género simposial y escribe un banquete ${ }^{22}$, que, sin em-

\footnotetext{
${ }^{19}$ Luc. Tim. 54-55.

${ }^{20} C f$. Murray (1990: 6).

${ }^{21} C f$. Brandâo (2001: 52).

${ }^{22}$ Cf. Amato (2005); Gómez \& Vintró (2008: 199-203).
} 
bargo, acaba convirtiéndose en un antibanquete ${ }^{23}$, desde el punto de vista del código literario. La definición de simposio socrático dada por los tratados de retórica remite, en esencia, a un contexto de digna cordialidad que lleva a la virtud ${ }^{24}$, mientras que el convite descrito por Luciano descubre una violenta y negativa है pıs entre los invita-

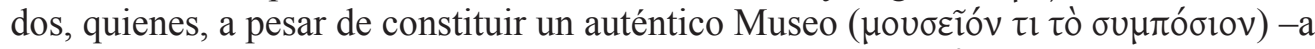
juzgar por la nutrida presencia de hombres sabios en ese festín ${ }^{25}$ - revelan una absoluta incapacidad para mantener una conversación instructiva, edificante o simplemente entretenida, puesto que la cortesía, la civilización, la armonía, las bromas oportunas adecuadas a una reunión simposial brillan por su ausencia en el convite relatado por Licino $^{26}$.

Desde esta perspectiva, en el Banquete, al motivo de la disputa entre los filósofos y, por lo tanto, también al de la crítica contra ellos, Luciano suma, de modo implícito, otros temas como la codicia, el desenfreno, la vanidad, las falsas apariencias. En efecto, en el banquete nupcial ofrecido por Aristéneto, a pesar de que Luciano se atiene a los componentes y tópicos propios del género, el código de conducta y el código social son bastante distintos a los que vehiculan los modelos usuales del género: sus invitados sólo imitan de forma ridícula a los distinguidos filósofos de la tradición simpótica socrático-platónica, e incluso a los eruditos de las charlas de sobremesa escritas por Plutarco ${ }^{27}$, y no pasan de ser violentos e incivilizados Centauros. Por ello, como el banquete es un lugar adecuado para que, entre risas y vino, también el hombre sabio muestre su sabiduría, Licino, al ver el deplorable espectáculo ofrecido por unos hombres pretendidamente sabios, se pregunta decepcionado: «¿De qué le sirve a alguien adquirir conocimientos, si no se ordena también la vida hacia el bien?» ${ }^{28}$.

Licino, no obstante, no imputa sólo a los efectos del vino el vergonzoso espectáculo presenciado en casa de Aristéneto; y sirve como prueba de ello la actitud del filósofo Hetemocles, quien, ausente de la celebración y, por lo tanto, sin haber par-

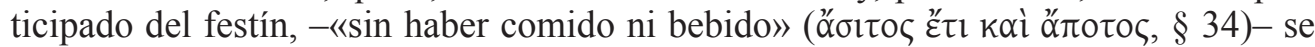
muestra tan indigno e insolente como los demás filósofos convidados cuando envía

${ }^{23}$ Cf. Bracht Branham (1989: 11-113); Gallardo (1972); Romeri (2002: 239-240). Sin embargo, en Luciano no hay sólo voluntad de parodiar un determinado género literario, aunque reproches semejantes a los que el samosatense dirige en su Banquete a los sabios y eruditos se encuentran asimismo en el texto de Ateneo, obra que también en algunos aspectos puede leerse como una parodia del género simposial; cf. Ath. IV 160 d-165 a; Jufresa (1997: 216); Anderson (2000: 323); Gómez \& Jufresa (2010: 99-100).

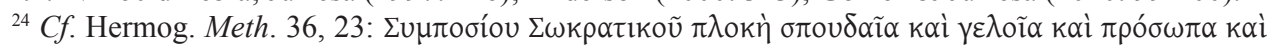

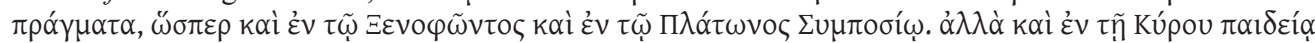

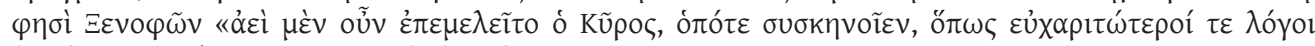

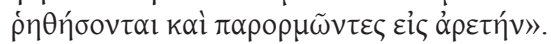

${ }^{25}$ Cf. Luc. Symp. 10.

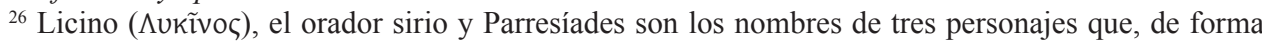
explícita, remiten al propio autor. Licino representa el doble ateniense de Luciano y, con un nombre cercano al suyo mismo ( $\Lambda$ oukı $\alpha$ vó $)$, el samosatense inviste de gran autoridad a este personaje que aparece en ocho diálogos; $c f$. Dubel (1994: 24-26).

${ }^{27}$ Cf. Frazier (1994: 130).

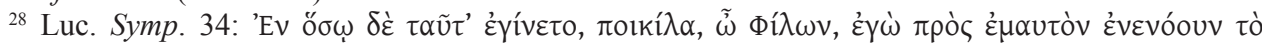

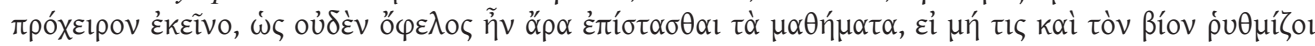

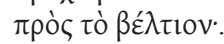


una carta al anfitrión para exigirle su ración de comida. Luciano contrapone el comportamiento de quienes hacen ostentación de saber con la actitud mantenida durante el banquete por el pueblo corriente, invitados anónimos, cuya conducta estuvo siempre

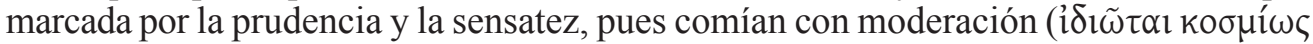

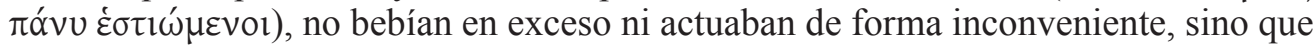
sólo «reían y se limitaban a censurar a los otros, creo, a quienes admiraban porque creían que eran alguien por sus vestiduras. Los sabios, por contra, eran groseros, se injuriaban, se hartaban sin medida, chillaban y se pegaban $\rangle^{29}$. En consecuencia, Licino atribuye la degradación del banquete de sabios a un deficiente y engañador uso de la paideia: «la educación aparta del recto razonamiento a quienes rígidamente fijen su mirada sólo en los libros y en los pensamientos que contienen ${ }^{30}$.

Frente a la hipocresía de los falsos eruditos, de los hombres que alardean de haber

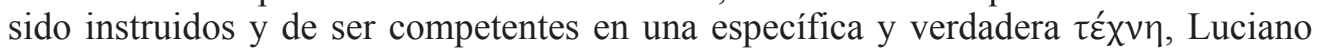
suele defender siempre cualquier modo de vida -válido también para el filósofo-que se base en una exaltación del sentido común tradicional, identificado en conceptos

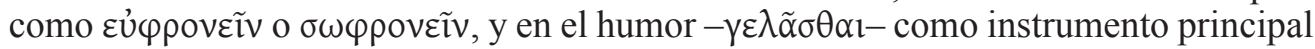
para no renunciar a ese sentido común, ya que la auténtica sabiduría no es sinónimo sólo de semblante grave y apariencia reflexiva, como suelen mostrarse siempre los filósofos ${ }^{31}$. Por ello, cuando Luciano quiere definir un sistema de valores marcado por la integridad, la honestidad y la verdad, distingue al platónico Nigrino de cuantos impostores filosofan, especulan y enseñan a jornal, pero ponen en venta la virtud ${ }^{32}, \mathrm{y}$, entre otros elogios, alaba la austeridad general de aquél, incluyendo también la gastronómica: «tampoco son escasos los ejemplos que ofrece a quienes deseen imitarle en cuanto a comida frugal, ejercicios gimnásticos moderados, noble rostro, sobrio atuendo $\mathrm{y}$, sobre todo, equilibrado entendimiento y dulce carácter» ${ }^{33}$.

\section{PARÁSITOS Y LAPITAS}

Como contrapunto al grotesco retrato de los filósofos en el banquete, en una obra que los escoliastas definen como un tratado de los más serios y, también, «el más

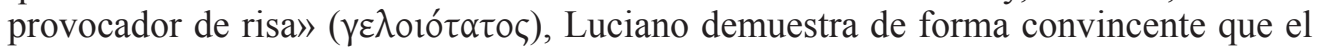
parasitismo es un arte de gran mérito, pues requiere grandes habilidades, esfuerzo y trabajo. Pero, al mismo tiempo, los argumentos esgrimidos en defensa del arte del parasitismo ponen de manifiesto que su objetivo es, en definitiva, idéntico al que persiguen siempre los filósofos en un banquete, en general, y los filósofos del Banquete de Luciano, en particular, ya que en éste los hombres sabios son, de hecho, unos auténticos parásitos, interesados sólo en satisfacer su glotonería, digna de feroces

${ }^{29}$ ibidem 35. También Filosofía distingue el comportamiento decoroso de la gente del montón frente a la inadecuada actitud de quienes dicen ser sus amigos (cf. Luc. Fug. 3). Para la contraposición i $\delta i \tilde{\omega} \tau \alpha \mathbf{l} /$ $\varphi$ ı

${ }^{30}$ Luc. Symp. 34.

${ }^{31} C f$. Luc. Nec. 21. Para la crítica de los falsos filósofos en Luciano, véase Jufresa (2003: 177-181).

${ }^{32}$ Cf. Luc. Nigr. 25; 33.

${ }^{33}$ ibidem 27. 
Centauros $^{34}$. No es de extrañar, pues, que Simón, el protagonista del diálogo titulado Acerca del parásito o que el parasitismo es un arte, prefiera mejor ser un parásito que ejercer de filósofo y se sienta orgulloso de poseer una $\tau \dot{x} \chi \vee \eta$ propia, definida por él mismo como «el arte de bebidas y comidas y de lo que se debe decir para lograrlas, que tiene como finalidad el placer» ${ }^{35}$.

De acuerdo con esta definición, la razón de ser del arte del parasitismo tal como es defendido y razonado por Simón, consiste en alcanzar el placer y la felicidad a través de la comida, pero ese fin es, en la tradición literaria griega, también un tema propio de la

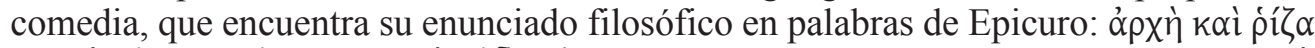

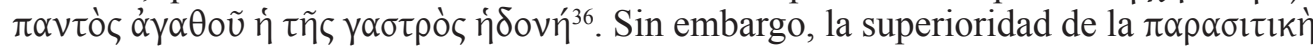
$\tau \varepsilon ́ \chi v \eta$ se basa en que el buen parásito logra su objetivo sin hipocresía y sin exponerse a las burlas ni al ridículo de que, en particular, se hacen acreedores los filósofos en el Banquete de Luciano, por su indigno comportamiento en este festín, aunque los farsantes acólitos de Filosofía son también motivo de sátira en otros muchos contextos en las obras de Luciano, donde, en general, igualmente obtienen su parte de censura cualquier falso erudito o individuo pretencioso: Lexífanes, el maestro de la nueva oratoria, el crítico falaz, el ignorante que compra libros ${ }^{37} \ldots$ Frente a todos ellos, el parásito se presenta como un hombre de condición libre, carente de posesiones, sin obligaciones, pero consciente y convencido de que su presencia es indispensable en casa de los ricos señores romanos para la escenificación de una celebración simposial ${ }^{38}$.

El parásito Simón, cuyo oficio es obtener sustento, manifiesta, no obstante, una sólida aptitud para argumentar y defender con ahínco sus puntos de vista, como si fuera un hombre instruido $-\mathrm{y}$ tal vez esa destreza pueda parecer tan impropia como la que exhiben los parásitos de Alcifrón, cuando con toda naturalidad citan a Homero ${ }^{39}$, Demóstenes $^{40} \mathrm{o}$ Teócrito ${ }^{41}$. Los filósofos, en cambio, son incapaces de razonar y de pensar en el contexto simposial, cuando el exceso de vino y, sobre todo, la disputa por los alimentos transforman a hombres aparentemente sabios en rudos Centauros -paradigma de brutalidad en el imaginario mítico de los griegos.

En casa de Aristéneto, la llegada de los $\tau \rho \alpha \gamma \eta ́ \mu \alpha \tau \alpha$ y de la cena completa -el llamado $\dot{\varepsilon} \vee \tau \varepsilon \lambda \dot{\varepsilon} \varsigma \delta \varepsilon \tilde{\imath} \tau \nu o v$ - consistente «en una gallina por persona, carne de jabalí y de liebre, fritura de pescado, pasteles de sésamo y dulces ${ }^{42}$, provoca una gran tensión entre los sabios hombres, cuando uno de ellos no se atiene como es debido a las pautas del banquete. El conflicto nace, precisamente, porque cada invitado debía tomar

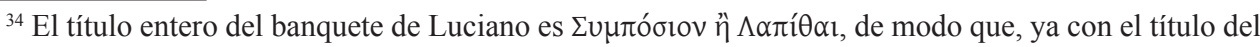
texto, Luciano intencionadamente remite a los lectores a un episodio mítico marcado por la insolencia y el exceso.

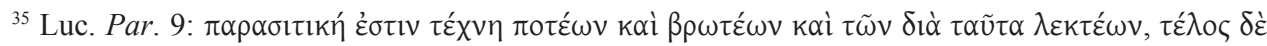

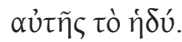

${ }^{36}$ Epicur. fr. 409 Usener (=Ath. VII 280 a; XII 546 f).

${ }^{37}$ Cf. Gómez (2003: 278); (2007: 490-493).

${ }^{38}$ Cf. Luc. Par. 58.

${ }^{39}$ Cf. Alciphr. III 42 y Il. III 365 u Od. XX 201; Alciphr. III 27 y Od. X 80-132.

${ }^{40} C f$. Alciphr. III 26 y D. XVIII 130.

${ }^{41} C f$. Alciphr. III 29 y Theoc. VII 82.

${ }^{42}$ Luc. Symp. 38.
} 
los alimentos que tenía delante o más cerca ${ }^{43}$; pero esa norma no es respetada por el estoico Zenótemis cuando ve que al epicúreo Hermón corresponden mayores porciones de comida que a él. De este modo, la dialéctica verbal, la rivalidad intelectual, el contraste de doctrinas, el intercambio de pensamiento, que nutren y justifican la charla de sobremesa quedan reducidos a una simple disputa y a una lucha física ${ }^{44}$, a un combate cuerpo a cuerpo entre los filósofos divididos en dos bandos: el peripatético Cleodemo ayuda al epicúreo Hermón; el cínico Alcidamante y el estoico Dífilo son los aliados de Zenótemis, él mismo también seguidor de Epicuro. Dífilo, por su parte, para hacerse con una buena ración de vianda, entabla con los sirvientes una batalla singular, de resonancias épicas: «estiraban la gallina aferrados como si arrastraran el cadáver de Patroclo» ${ }^{45}$. En este contexto, los alimentos que en el banquete erudito de Ateneo son objeto de discusión, charla y comentario en una parte de la celebración convival ${ }^{46}$, se convierten ahora en armas burlescas y objeto de contienda para unos Centauros ridículos, que se disputan la comida agarrándose por las barbas ( $\tau \tilde{\omega} v$

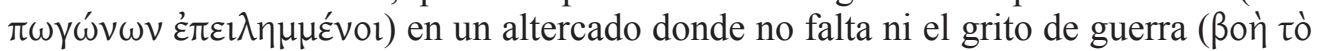

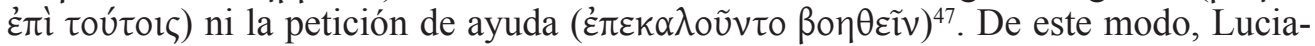
no, cuando reúne a los filósofos en un banquete, convierte en una escena irrisoria la tradicionalmente intelectual discordia entre hombres sabios, quienes, lejos de dominar saber alguno durante el ágape nupcial de Cleantis y Quereas, a pesar de hacer ostentación de ello, sólo se muestran idóneos para generar una violencia de tal magnitud que la sala de la celebración se transforma en un auténtico campo de batalla: «Lapitas y Centauros habrías visto, mesas giradas, sangre derramada y copas por el aire ${ }^{48}$.

Simón, en cambio, reconoce que quizás su arte puede parecer sorprendente ( $\pi \alpha \rho \alpha ́ \delta \circ \xi o v)$, pero cumple todos los requisitos para ser considerado como tal. Un arte es según los sabios -afirma Simón- «un sistema de conocimientos ejercidos en combinación para un fin útil a la vida ${ }^{49}$. Y, en efecto, el parasitismo conlleva poner en práctica, a diario y de modo constante, unos conocimientos: la condición de parásito exige averiguar quién da alimento; obliga a saber cómo son esos alimentos y a ser capaz de obtenerlos en abundancia. Pero, además, sin duda alguna, el propósito de su arte es el más útil para la vida: ¿cómo vivir sin comer ni beber ${ }^{50}$ ?. No obstante, para defenderse a sí mismo y a su propio arte, Simón toma como referente a los filósofos para acusarles, precisamente, de ladrones, y, entre ellos, de modo especial a Epicuro.

\footnotetext{
${ }^{43}$ Plutarco (Moralia 643 a-644 e) plantea si en un banquete es mejor comer por raciones, como hacían los antiguos, o en común.

${ }^{44}$ Cf. Romeri (2002: 211).

${ }^{45}$ Luc. Symp. 42. El efecto paródico de la asimilación de un trozo de ave al cadáver de Patroclo, recuerda las palabras del ratón Robamigas cuando explica su linaje y sus gestas, centradas en la obtención de alimento; $c f$. Hom., Batr. 24-55.

${ }^{46}$ Ateneo dedica especial atención a temas como el vino (I 35 a-40 f), los entrantes (II 49 e-71 e), las clases de panes (III $108 \mathrm{f}-116 \mathrm{a}$ ), las salazones (III $116 \mathrm{~b}-121 \mathrm{c}$ ), los peces y pescados (VII $276 \mathrm{e}-330 \mathrm{c}$ ) o los pasteles (XIV 649 c-e).

${ }^{47}$ Luc. Symp. 43.

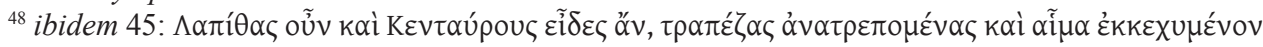

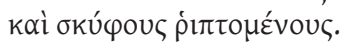

${ }^{49}$ Luc. Par. 4.

${ }^{50}$ ibidem 7.
} 
Simón podría reconocerse como un hombre sin instrucción, pero argumenta que los filósofos -individuos de fingida ilustración- en nombre de la filosofía pretenden usurparle a él el objetivo único de su razón de ser: la felicidad. La prueba de que se sirve para demostrar que la felicidad jamás podrá pertenecer a los filósofos es que éstos se nutren de palabras huecas y de argumentos erróneos, de modo que, a diferencia del parásito, con tales recursos nunca alcanzarán el placer, que consiste en la imperturba-

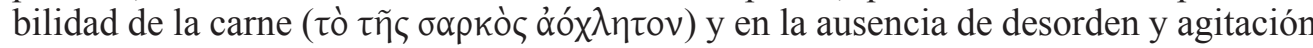

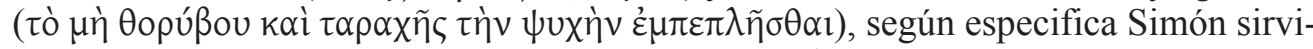
éndose, a su vez, de terminología filosófica, estoica ${ }^{51}$.

Por otra parte, el parasitismo es el mejor arte, tanto si se compara con las demás artes en general, como con algunas en particular. El parasitismo es un arte ejercido siempre en un contexto festivo y de amistad; es más, emulando al propio Epicuro, Simón se atreve a formular, categórico, que la $\varphi \imath \lambda i ́ \alpha$ misma no es otra cosa que el

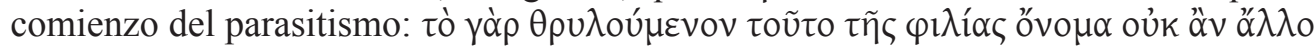

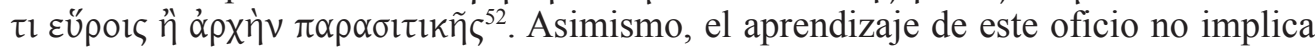
temores ni azotes; no requiere tampoco esfuerzo alguno ni herramientas ni dinero para pagar a falsos maestros. No obstante, es significativo que para una comparación particular, Simón elija, precisamente, la retórica y la filosofía, calificándolas como las artes más bellas y más importantes, «a las que por su nobleza, algunos consideran incluso ciencias $\rangle^{53}$. Frente a la vacuidad de ambas, el parasitismo se revela como un arte que tiene un fundamento substancial ( $\tau \dot{v} v$ úró $\sigma \tau \alpha \sigma l v$ ); aquellas, en cambio, carecen por completo de él. Por ejemplo, cada uno tiene una opinión distinta de la retórica: es un

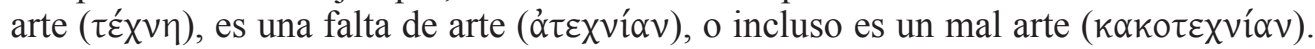
Y la filosofía tampoco es uniforme e idéntica: «cada uno proclama que la filosofía es algo diferente de lo que dicen los otros $\rangle^{54}$.

Por contra, Simón defiende la unidad esencial de su arte como algo natural e indiscutible: «el parasitismo, en cambio, no es así, sino que tanto entre griegos como

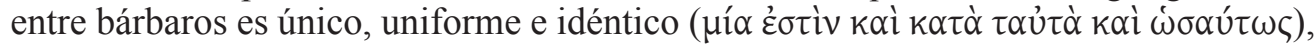
y nadie podría decir que unos son unos parásitos de un modo y otros de otro. Ni hay, según parece, entre los parásitos, grupos como los estoicos o los epicúreos, que sostienen doctrinas diferentes. Al contrario, existe entre todos y con todos un asentimiento y

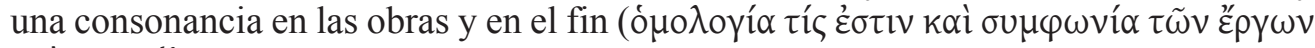

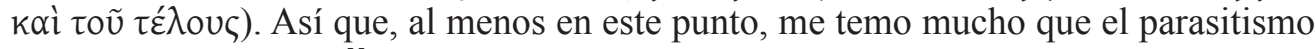
es también sabiduría $»^{55}$.

El ejemplo de Trasicles o la pelea de los filósofos por atrapar una suculenta porción de comida en el Symposium de Luciano, evidencian negativamente que tal vez la diversidad de parecer entre los supuestos sabios a los que se refiere Simón, sólo se neutraliza cuando se trata de comer y de beber.

\footnotetext{
${ }^{51}$ ibidem 11; cf. Nesselrath (1985: 311-317).

${ }^{52}$ Luc. Par. 22.

${ }^{53}$ ibidem 26; cf. Nesselrath (1985: 357-369).

${ }^{54}$ Luc. Par. 27.

${ }^{55}$ ibidem 30.
} 
También Hermotimo - cuyo nombre da título a una de las obras donde Luciano, de nuevo a través de Licino ${ }^{56}$, arremete con mayor contundencia contra las escuelas filosóficas- se ve perjudicado por el nefasto comportamiento de los filósofos en el banquete, cuando no puede recibir lecciones de filosofía por indisposición de su maestro, un estoico, justo al día siguiente de que éste hubiera asistido a un convite. Durante la celebración simposial -explica Luciano- los asistentes hablaron mucho de filosofía y los representantes de las distintas escuelas filosóficas discutieron también entre ellos, como es habitual en una reunión de este tipo. Pero el verdadero motivo de que el maestro filósofo esté ausente de su escuela es, en realidad, el terrible dolor de cabeza y la indigestión que padece por haber comido y bebido mucho más de lo que conviene a un hombre demasiado mayor, de modo que la disputa y la controversia filosófica fueron algo más que palabras: Eutidemo, un representante de la escuela peripatética en dicha celebración, se fue de la fiesta herido, con sangre y una brecha en la cabeza, pues su rival estoico, el maestro de Hermotimo, no tuvo reparo alguno en agredirlo con una copa, dado su estado de embriaguez ${ }^{57}$.

La conducta habitual de los filósofos en el banquete se perpetúa incluso post mortem. En la Isla de los Bienaventurados, que magistralmente Luciano describe en el libro segundo de sus Verae Historiae ${ }^{58}$, los seguidores de Aristipo y de Epicuro ocupan un lugar preferente en el festín de los Campos Elisios, al ser «dulces y agrada-

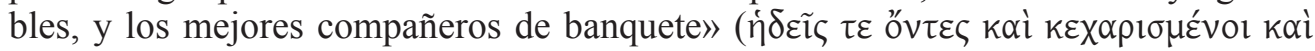
$\left.\sigma \cup \mu \pi 0 \tau i k \omega ́ \tau \alpha \tau 0^{59}\right)$; y allí también el cínico Diógenes de Sínope, casado ahora con la hetera Lais, ha adoptado, sin escrúpulos, como Alcidamante en casa de Aristéneto ${ }^{60}$, los vicios simposiales de los filósofos de las restantes escuelas: ebrio siempre, a menudo se levanta para bailar, se comporta con escasa dignidad y gasta bromas inconvenientes propias de un borracho ${ }^{61}$.

Sin embargo, a diferencia de los sabios en apariencia y por pura convención, los

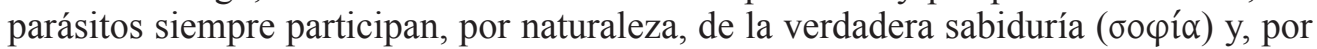
ello, no se ven obligados jamás a anhelarla, a ser simples diletantes de esa sabiduría («filo-sofía»), a querer ser, en definitiva, filósofos, mientras que todos los filósofos, como carecen de auténtico saber, aman necesariamente el parasitismo, aspiran a él. Y lo aman por su utilidad, por su fin, pero también porque el parásito supera con creces al filósofo tanto en el aspecto físico y en el modo de vida, como incluso en la muerte,

${ }^{56}$ supra n. 26.

${ }^{57}$ Cf. Luc. Herm. 11-12. Plutarco (Moralia 618 e) recomienda que los poetas o los sofistas no se sienten entre ellos juntos en el banquete, y evitar así que sus particulares rivalidades puedan estropear la buena armonía de la celebración.

${ }^{58}$ Georgiadou \& Larmour (1998: 94-95), consideran que incluso la batalla entre heliotas y selenitas en Relatos verídicos es un reflejo de la disputa entre escuelas filosóficas alentada en el escepticismo de la Academia nueva y no sólo un espejo de la tradición homérica.

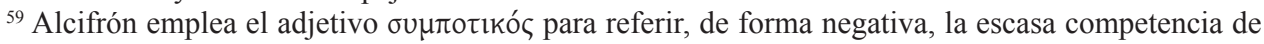
los corintios en la celebración simposial por beber «un vino ardiente y abrasador, sin mezcla de agua» (Alciphr. III 15). El poeta cómico Alexis (fr. 292 K.-A. = Ath. I 30 f) se hace eco de la pésima calidad y aspereza del vino corintio hasta el punto de calificarlo como una «tortura» ( $\beta \alpha \sigma \alpha v ı \sigma \mu o ́ \varsigma) ; ~ c f$. Montañés (2008: 212, n. 222).

${ }^{60}$ Cf. Luc. Symp. 12-13. Véase Nesselrath (1998: 133).

${ }^{61}$ Cf. Luc. VH 218. 
pues incluso en esa circunstancia, cuando ocurre tras comer y beber, el parásito alcanza siempre la felicidad: ¡la única muerte violenta posible es la indigestión ${ }^{62}$ ! Además, el buen parásito es de apariencia fuerte y robusto, de carácter jovial y animoso, tiene un agradable color de piel, y posee una mirada altanera y terrible, pero el filósofo parece siempre un simple mendigo: barba, bastón y manto raído son sus constantes atributos $^{63}$. En consecuencia, si la felicidad consiste en no pasar hambre ni sed ni frío, un parásito siempre será feliz y mucho más afortunado que cualquier filósofo, ya que la mayoría de éstos pasan hambre y sed ${ }^{64}$.

De este modo, la vida del parásito, libre de aflicción, de cólera, de envidias, carente de cualquier deseo, transcurre apacible y nada enturbia su felicidad. Por contra, tres males ineludibles, e incurables, aquejan y consumen a todos los hombres ilustrados,

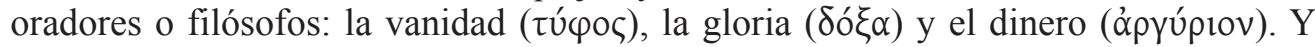
así lo explica Simón a Tiquíades: «los oradores, en cambio, y -lo que es más terrible- también los que afirman ser filósofos se encuentran de manera tan miserable afectados, que, entre los más reputados filósofos de ahora - ¿para qué hablar de los oradores?- a uno, cuando actúa como juez, lo atrapan culpable de soborno; otro exige una paga al rey por aconsejarle, y no se avergüenza si a causa de ello, en su vejez, vive exiliado y gana un sueldo como un prisionero de guerra indio o escita, y ni siquiera se avergüenza del nombre que por ello recibe ${ }^{65}$.

Los filósofos y oradores son, pues, a ojos de Simón unos simples mercenarios, sometidos a la voluntad y al capricho de quienes se postulan como amantes del saber por el mero hecho de hacerse acompañar por algún individuo de barba larga y que vista con porte el manto griego. Pero, lo que es peor aún para el parásito Simón es que éstos -sean gramáticos, oradores o filósofos- estén dispuestos a aceptar dinero por el mero hecho de lucir esa barba, de vestir ese manto o, simplemente, llevar un libro en las manos ${ }^{66}$.

Luciano quiere insistir en ello y termina el diálogo con un juego etimológico sobre el propio nombre del parasitismo ( «comer al lado de alguien»), que permite asimilar al sincero y noble parásito el comportamiento indigno y falso de los $\pi \varepsilon \pi \alpha 1 \delta \varepsilon \cup \mu \varepsilon ́ v o 1$ -filósofos y hombres de letras, en general- por comparación, esta vez positiva, con otras actividades que no se considera vergonzoso realizar «con alguien al lado» $(\pi \alpha \rho \alpha-)$. Mediante el método dialéctico utilizado a lo largo de la obra, Simón plantea a su interlocutor el siguiente razonamiento: si los antiguos llamaban alimento ( $\sigma \tilde{\imath} \tau o v)$ al

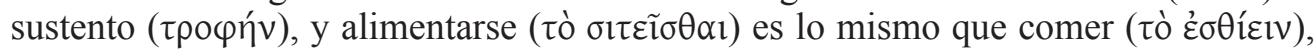
entonces practicar el parasitismo ( $\pi \alpha \rho \alpha \sigma l \tau \varepsilon \tilde{\imath} v)$, no es otra cosa que procurarse sustento junto a alguien ${ }^{67}$. Es decir, satisfacer sin engaño la carencia de alimento ${ }^{68}$.

${ }^{62}$ Cf. Luc. Par. 57. No obstante, algunos parásitos de Alcifrón denuncian en sus cartas las malas prácticas simposiales de ciertos anfitriones cuyo comportamiento, pone en peligro la vida de los parásitos al obligarles a comer y a beber más de lo debido; $c f$. Alciphr. III 4.

${ }^{63}$ Cf. Luc. Par. 38.

${ }^{64}$ Cf. García Valdés (2001: 234-235), sobre el problema textual del pasaje.

${ }^{65}$ Luc. Par. 52.

${ }^{66}$ Cf. Luc. Merc. Cond. 25.

${ }^{67}$ Cf. Luc. Par. 60-61.

${ }^{68}$ En la etimología del término parasitismo se revela asimismo el papel central de los cereales, y del

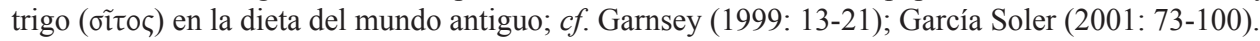




\section{CONCLUSIONES}

Luciano, cuando a través del banquete como institución arragaida en la tradición griega y mantenida en la sociedad romana, piensa, al mismo tiempo, en la necesidad esencial del hombre de alimentarse, dirige también su mirada crítica hacia la cultura contemporánea, para denunciar cómo la paideia, símbolo de identidad griega, se ha convertido en un espectáculo comercial, en un mundo dominado por Roma ${ }^{69}$. En un universo social diferente al de la polis clásica, se ha producido un cambio de status de los filósofos y eruditos, de quienes trata de diferenciarse el parásito Simón ${ }^{70}$. Platón buscaba la consolidación de un espacio para la filosofía y para los filósofos propio y distinto al de los sofistas ${ }^{71}$; en el s. II d.C., Luciano trata, en cambio, de salvar la auténtica filosofía y de restaurar la imagen de los verdaderos filósofos, para distinguirlos de los sofistas y petulantes $\pi \varepsilon \pi \alpha 1 \delta \varepsilon u \mu \varepsilon ́ v o 1^{72}$, que proliferaban en una época en la que aquellos que se hacían llamar maestros o eran especialmente educados gozaban de gran prestigio social e incluso participaban activamente en la vida política local ${ }^{73}$. La cultura filosófica, más que en un fin en sí misma, se había convertido en un espectáculo comercial y en un elemento de distinción entre la clase dominante ${ }^{74}$, a la cual los filósofos, maestros, rétores y gramáticos, a modo de esclavos y bajo el pretexto de instruirlos, prestan sus servicios en pésimas condiciones y de forma indigna, sufren, en realidad, toda suerte de calamidades y desprecios, padeciendo hambre y sed, sin escapar de la pobreza ${ }^{75}$. A diferencia de éstos, no es jamás un pobre mendigo el parásito -Simón mismo se autoproclama $\delta \eta \mu 10 u \rho \gamma o ́ \varsigma^{76}-$, sino el rico que se adorna gracias al parásito, pues sin éste, a pesar de toda su riqueza, no se distingue de un hombre humilde y vulgar.

${ }^{69}$ Cf. Whitmarsh (2001: 258 y 293).

${ }^{70}$ Bracht Branham (1989: 121-123), explica el desafortunado festín nupcial del Symposium de Luciano en razón de este cambio, y no sólo como una muestra ejemplar de la diatriba satírica menipea. Helm (1906) consideró muy importante la influencia de Menipo de Gádara en la obra de Luciano, pero Bompaire (1958: 335-378), y otros críticos tras él, han negado que Menipo sea la única fuente de Luciano; cf. Hall (1981: 64-150).

${ }^{71}$ Solón considera educadores de Atenas tanto a los sofistas como a los filósofos ( $c f$. Luc. Anach. 22), pero los filósofos eran vistos todavía con una mezcla de suspicacia y de menosprecio en la Atenas clásica (cf. Pl. Grg 485 a-c; 487 c).

${ }^{72}$ Cf. Anderson (1989: 87-88; 118-123).

${ }^{73}$ Como ilustra Filóstrato en Vidas de sofistas, tanto en relación con la propia ciudad como a las ciudades donde ejercían de maestros y de sofistas. En Atenas, Herodes Ático fue arconte (VS 549) y Loliano de Éfeso estratega (VS 526). En cambio, Favorino tuvo que enfrentarse a un proceso judicial por rechazar servicios públicos (VS 489), y Elio Arístides explica él mismo cómo consiguió eludirlos (Or. L 71-99 K).

${ }^{74}$ Obras como Adversum indoctum o De mercede conductis son un buen ejemplo de ello; $c f$. Whitmarsh (2001: 248-294).

${ }^{75}$ Cf. Luc. Merc. Cond. 4, 26; Apol. 12.

${ }^{76}$ Cf. Luc. Par. 2. 


\section{BIBLIOGRAFÍA}

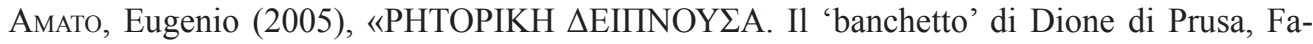
vorino e Luciano», Euphrosyne 33: 341-353.

Anderson, Graham (1976), Theme and Variation in The Second Sophistic, Leiden.

- (1989), «The pepaideumenos in Action: Sophist and their Outlook in the Early Empire», $A N R W$ II 33.1: 79-208.

- (2000), «The Banquet of Belles-Lettres. Athenaeus and the Comic Symposium» en D. Braund - J. Wilkins (eds.), Athenaeus and his World. Reading Greek Culture in the Roman Empire. Exeter: 316-326.

Bompaire, Jacques (1958), Lucien écrivain. Imitation et création. Paris.

- (1998), «Notice à Le Banquet ou les Lapithes» en Lucien. Oeuvres II. Opuscles 10-20. Paris: 189-199.

Bracht Branham, Robert (1989), Unruly Eloquence. Lucian and the Comedy of Traditions. Cambridge-London.

BrandÂo, Jacyntho Lins (2001), A poética do Hipocentauro. Literatura, sociedade e discurso ficcional em Luciano de Samósata. Belo Horizonte.

Dubel, Sandrine (1994), «Dialogue et autoportrait: les masques de Lucien» en A. Billault (ed.), Lucien de Samosate. Paris: 19-26.

Frazier, Françoise (1994), «Deux images des Banquets de Lettrés: les Propos de Table de Plutarque et le Banquet de Lucien» en A. Billault (ed.), Lucien de Samosate. Paris: 125-130.

Gallardo, María Dolores (1972), «Los Simposios de Luciano, Ateneo, Metodio y Juliano», CFC 4: 239-296.

García Soler, María José (2001), El arte de comer en la Antigua Grecia. Madrid.

GARCÍA VALDÉs, Manuela (2001), «Estudio crítico-textual de El arte del parasitismo de Luciano», Emerita LXIX 2: 225-240.

García VAldÉs, Manuela (2004), Luciano. Obras VI. Madrid.

Garnsey, Peter (1999), Food and Society in Classical Antiquity. Cambridge.

Georgiadou, Aristoula \& Larmour, David H.J. (1998), Lucian's Science Fiction Novel True Histories. Interpretation \& Commentary. Leiden-Boston-Köln.

Gómez, Pilar (2003), «Sofistas, según Luciano» en J.Ma Nieto Ibáñez (coord.), Lógos hellenikós. Homenaje al Profesor Gaspar Morocho Gayo, vol. I. León: 277-284.

- (2007), «Luciano y la escuela» en J.A. Fernández Delgado-F. Pordomingo-A. Stramaglia (eds.), Escuela y literatura en Grecia antigua. Cassino: 485-496.

Gómez, Pilar \& Jufresa, Montserrat (1999), «La risa y el vino en los escritos simposíacos de Plutarco» en J.G. Montes-M. Sánchez-R.J. Gallé (eds.), Plutarco, Dioniso y el vino. Madrid: $255-267$.

GómEz, Pilar \& VinTró, Eulàlia (2008), «Gastronomic philosophy, or the pepaideumenos as parasite» en M. Çevik (ed.), International Symposium on Lucianus of Samosata. Adiyaman: 191-206.

Gómez, Pilar \& JufresA, Montserrat (2010), «Llucià a taula: aliments i simposi» en F. Mestre-P. Gómez (eds.), Lucian of Samosata. Greek Writer and Roman Citizen. Barcelona: 99-113.

GonzÁlez Julià, Lluís (2009), «La Téchne rhetoriké de Plutarco para el simposio en la Quaestiones convivales: hablar bien para cuidar la amistad» en J. Ribeiro Ferreira-D. Leão-M. Tröster-P. Barata Dias (eds.), Philanthropia and Symposium in Plutarch. Coimbra: 63-74. 
HaLl, Jennifer (1981), Lucian's Satire. New York.

Helm, Rudolf (1906), Lukian und Menipp. Leipzig 1906 (reimp. Hildesheim 1966).

Jufresa, Montserrat (1997), «Epicur, vist per Ateneu» en M. del C. Bosch-M.A. Fornés (eds.), Homenatge a Miquel Dolç. Palma de Mallorca: 215-218.

— (2003), «El teatre, metàfora de la vida a Llucià», Ítaca 19: 171-186.

Jufresa, Montserrat \& FAU, M. Teresa (2001), «Referències alimentàries en alguns mites de fundació de ciutats gregues», Monografies 2. MAC-Barcelona. Barcelona: 189-192.

Mestre, Francesca (1997), «Retórica y diálogo contra el sirio», Synthesis 4: 21-31.

Mestre, Francesca \& Gómez, Pilar (2001), «Retórica, comedia, diálogo. La fusión de géneros en la literatura griega tardía», Myrtia 16: 111-122.

Mestre, Francesca \& Gómez, Pilar (2007), Luciano. Obras IV. Madrid.

Montañés, Rubén (2008), Alexis. Fragments de Comèdies. Barcelona.

Murray, Oswyn (ed.) (1990), SYMPOTICA. A symposium on the Symposion. Oxford.

Nesselrath, Heinz-Günther (1985), Lukians Parasitendialog. Berlin-New York.

- (1998), «Lucien et le Cynisne», AC 67: 121-135.

ReARdon, Bryan (1971), Courants littéraires grecs des IIè et IIIè siècles après J.-C. Paris.

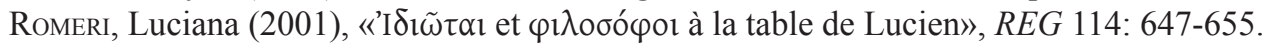

- (2002), Philosophes entre mots et mets. Plutarque, Lucien et Athénée autour de la table de Platon. Grenoble.

Romm, James (1990), «Wax, Stone and Promethean Clay: Lucian as Plastic Artist», ClAnt. 9: 74-98.

Whitmarsh, Tim (2001), Greek Literature and the Roman Empire. The Politics of Imitation. Oxford. 